\title{
Heterogeneous intra-annual climatic changes drive different phenological responses at two trophic levels
}

\author{
Hideyuki Doi ${ }^{1,4, *}$, Oscar Gordo ${ }^{2}$, Izumi Katano ${ }^{3}$ \\ ${ }^{1}$ School of Aquatic and Fishery Sciences, University of Washington, Box 355020, Seattle, Washington 98195, USA \\ ${ }^{2}$ Departamento de Ecología Evolutiva, Museo Nacional de Ciencias Naturales (CSIC), C/ José Gutiérrez Abascal 2, \\ 28006 Madrid, Spain
}

${ }^{3}$ Aqua Restoration Research Center (ARRC), Public Works Research Institute, Kawashima Kasada-machi, Kakamigahara, Gifu 501-6021, Japan

${ }^{4}$ Present address: LAFWEDY, Faculty of Agriculture, Ehime University, 3-5-7, Tarumi, Matsuyama, $790-8566$ Ehime, Japan

\begin{abstract}
A shift in a life cycle event of one species relative to other species in an ecosystem should be considered more relevant than an absolute shift in phenological dates. However, there is very little evidence regarding the differential effects of climate change on the phenologies of different trophic levels and their potential effects on ecosystem functioning. The Japan Meteorological Agency has monitored the flowering of 4 Prunus tree species and the appearance date of the butterfly Pieris rapae (a proxy for potential pollinators) in spring at Nagano, Japan, since 1953. Flowering tended to occur earlier over the last 3 decades, whereas the appearance of the butterfly was delayed. The effects of climate and the timing of the sensitive period differ between both trophic levels. The plants were strongly affected by temperature $(\mathrm{r}=-0.87) 30$ to $40 \mathrm{~d}$ prior to flowering, whereas the butterfly was less affected by temperature $(\mathrm{r}=-0.50)$, and the effects mainly occurred during the $15 \mathrm{~d}$ prior to its appearance. The temperature during the plants' sensitive period has increased sharply since 1953, whereas the temperature during the butterfly's sensitive period has not changed significantly. The phenologies of the plants and butterfly are changing in opposite directions because they use different climatic cues with different temporal trends. This is the first documentation of differential effects of climate change between plant and insect phenology in Japan.
\end{abstract}

KEY WORDS: Prunus · Flowering · Global warming · Insect appearance · Daily temperature · Phenology $\cdot$ Pieris rapae

Resale or republication not permitted without written consent of the publisher

\section{INTRODUCTION}

Spring phenological events such as flowering, leaf unfolding, insect appearance, or migratory bird arrival are now occurring earlier than in past decades (Walther et al. 2002, Root et al. 2003, Menzel et al. 2006, Parmesan 2006, Jonzén et al. 2007). This advancement of organisms' life cycles in the spring is attributed to climate change (Root et al. 2003), because climate controls phenology in many species. In plants, the timing of life cycle events is strongly affected by climate, because the plants are fixed and obligated to endure weather conditions where they live. The onset of spring events such as leaf and flower unfolding is especially sensitive to climate (Menzel 2003, Gordo \& Sanz 2005, Wolfe et al. 2005). Insects are also strongly dependent on climate, because they are small poikilotherms, and their thermoregulation is strongly affected by temperature. Insect activity and development are shifting in response to global climate change (e.g. Gordo \& Sanz 2006, Sparks et al. 2007). 
Climate change can affect physical and biological processes differently and can have different effects on different trophic levels (Inouye et al. 2000, Visser \& Both 2005). In fact, understanding a shift in the life cycle of one species relative to other species in an ecosystem is more important than understanding an absolute shift in phenology (Visser \& Both 2005), because this is the only way to determine whether species are effectively responding to climate change challenges. Only a few studies have addressed the question of altered synchrony between species (Harrington et al. 1999, Stenseth \& Mysterud 2002, Visser \& Both 2005). However, they offer irrefutable evidence that climate change is affecting inter-specific interactions, such as those between primary producers and herbivores (e.g. Visser \& Holleman 2001, Bale et al. 2002) or between pollinators and plants (Gordo \& Sanz 2005, Memmott et al. 2007) due to the differential alteration of the life cycles of the interacting species. These studies also suggest that the mismatching of interactions can affect population viability; therefore, a loss of biodiversity is expected (Visser et al. 2004, Visser \& Both 2005, Memmott et al. 2007). Interestingly, despite the importance of matching between trophic levels and the strong evolutionary pressures to maintain the match, each species uses a different climatic cue to regulate its phenology (e.g. Inouye et al. 2000, Both \& Visser 2001, Gordo \& Sanz 2005). Consequently, if the climatic cues used by each species change at different rates because of heterogeneous spatial or temporal (i.e. within-year) climate trends (e.g. Easterling et al. 1997), then a decoupling between species is expected.

We examined long-term trends in plant and insect spring phenology over several decades and determined the role of recent climate change in the differential responses between 2 trophic levels. We studied flowering time in 4 species of Prunus (cherry and apricot) trees and the appearance of the butterfly Pieris rapae in the spring in Japan, where effects of climate change on biota have been rarely studied (e.g. Matsumoto et al. 2003, Doi 2007, Doi \& Katano 2008). We aim to offer insights about the potential mismatch between 2 dependent trophic levels by means of a comprehensive search of the underlying climatic mechanisms driving phenology in each of them.

\section{MATERIALS AND METHODS}

\subsection{Phenology dataset}

The flowering time of 4 species of the genus Prunus ( $P$. davidiana, $P . \times$ yedoensis, $P$. pendula form. ascendens, and $P$. armeniaca) was monitored by the Japan Meteorological Agency (JMA) at the Nagano Observa- tory (36³9'36"N, 138 ${ }^{\circ} 11^{\prime} 42^{\prime \prime} \mathrm{E}_{\text {; }}$ elevation: $418 \mathrm{~m}$ above sea level). The JMA recorded the date when 5 to 6 buds flowered (hereafter 'flower unfolding') and the date when approximately 80 to $100 \%$ of buds flowered (hereafter 'full flowering') each year from 1953 to 2002 (JMA 1985). A third variable was calculated: the flowering speed, defined as the number of days between flower unfolding and full flowering.

The JMA also recorded the date on which an adult Pieris rapae first appeared each year from 1953 to 2002 (excepting 1989 and 1992) in the environs of Nagano Observatory. $P$. rapae is a non-specialized pollinator and is the dominant species in the butterfly community during the spring in central Japan (Inoue 2004). Therefore, the interaction between $P$. rapae and Prunus flowers is highly probable. Furthermore, $P$. rapae could also be considered as a proxy for the insect pollinator guild of Prunus species. Such an assumption is based on the demonstrated sensitivity of this species to climate, which is quite similar to the influence of climate over other important and well-established pollinator species of Prunus species (e.g. Gordo \& Sanz 2006). To determine the degree of coupling between butterfly appearance and Prunus flowering, for each Prunus species, we calculated 'mismatching days' as the number of days between the first appearance of $P$. rapae and flower unfolding.

\subsection{Climate dataset}

We used air temperature and total precipitation at the Nagano Observatory from 1953 to 2002. A daily climate dataset was only available from 1961 to 2002 (except 1989); thus, climatic assessment over phenology was restricted to this shorter period. Using the daily dataset, we evaluated the effect of climate on the phenological events during different time intervals in a complete annual cycle (i.e. 365 d). For this purpose, the average daily temperature and the sum of daily precipitation were calculated for 13 time windows ranging from 1 to $60 \mathrm{~d}$, at intervals of $5 \mathrm{~d}$ (i.e. 1, 5, 10, .., and 60), for all days from 1961 to 2002. Therefore, for each day of the year we obtained the average temperatures or the total amount of precipitation for the $5,10,15, \ldots$, and 60 preceding days. The starting point of the annual cycle was 1 May of the previous year and ended on 30 April of the year in which events were recorded.

\subsection{Statistical analyses}

Regression analyses were performed to determine the occurrence of long-term temporal trends in plant 
and insect phenology for 2 periods: 1953-2002 and 1970-2002. For the period 1953-2002, non-linear trends were modeled by means of second-order polynomials. Such quadratic functions were fitted to data only when both linear and quadratic terms of the polynomial were significant at $\mathrm{p}<0.05$. Otherwise linear regressions were calculated. For the period from 1970-2002, linear regression models were fitted to all phenological time series.

The temporal trends in annual mean temperature and total precipitation were also evaluated separately for these 2 periods. The analysis for the period 19532002 allowed us to detect long-term climatic changes at the study site. Linear regression analyses were then performed for each day of the year for the 13 time windows to investigate intra-annual variability in temporal trends of temperature and precipitation for the period 1970-2002. We calculated temporal trends for this shorter period because temperature and precipitation fluctuated during the period 1953-2002 and have only shifted steadily since the 1970s (see Fig. 3).

Pearson's correlation coefficients were calculated for each phenological time series (i.e. flower unfolding and full flowering in the 4 Prunus species and Pieris rapae appearance), and temperature and precipitation were calculated for each of the 13 time windows for the preceding $365 \mathrm{~d}$ to the average phenophase date of occurrence. This approach allowed us to identify the most correlated periods (i.e. time windows) for temperature and/or precipitation within the preceding year for each phenological event. A comparison of the correlation coefficients for the same day obtained with different time windows allowed us to determine the amplitude of the sensitive window.

\section{RESULTS}

\subsection{Temporal trends in phenological events}

Flower unfolding and full flowering occurred about $12 \mathrm{~d}$ earlier in Prunus davidiana than in the other Prunus species (Table 1). The flowering speed of this species was also somewhat slower than those of the other species. The first Pieris rapae individuals appeared about $1 \mathrm{wk}$ after the onset of flowering of $P$. davidiana and about $1 \mathrm{wk}$ before the flowering of the rest of species.

For the period 1953-2002, quadratic models were the best fitted temporal trends in flower unfolding and full flowering in most Prunus species (Table 1). In all Prunus species the long-term variability in flowering dates was quite similar to that shown in Fig. 1A for $P$. yedoensis, but in the cases of the flower unfolding of P. davidiana $\left(\mathrm{R}^{2}=9.68 \%, \mathrm{p}=0.091\right)$ and $P$. armeniaca

Table 1. Prunus spp. and Pieris rapae. Regression models for temporal trends in phenology. Mean is the average date of each phenological event, or the average number of days of flowering speed or mismatching days for each species. Year and Year ${ }^{2}$ are the slope for the linear and quadratic terms, respectively (SE: standard error)

\begin{tabular}{|c|c|c|c|c|c|c|c|c|}
\hline \multirow[t]{2}{*}{ Species } & \multirow{2}{*}{ Mean } & \multicolumn{4}{|c|}{ Period 1953-2002 } & \multicolumn{3}{|c|}{ Period 1970-2002 } \\
\hline & & Year $\pm \mathrm{SE}$ & Year $^{2} \pm \mathrm{SE}$ & $\mathrm{R}^{2}$ & $\mathrm{p}$ & Year $\pm \mathrm{SE}$ & $\mathrm{R}^{2}$ & $\mathrm{p}$ \\
\hline \multicolumn{9}{|c|}{ Flower unfolding } \\
\hline P. davidiana & 26 Mar & $-0.076 \pm 0.072$ & & 2.24 & 0.299 & $-0.270 \pm 0.143$ & 10.39 & 0.067 \\
\hline P. yedoensis & 8 Apr & $39.45 \pm 15.02$ & $-0.010 \pm 0.004$ & 13.59 & 0.032 & $-0.223 \pm 0.100$ & 13.85 & 0.033 \\
\hline P. armeniaca & $9 \mathrm{Apr}$ & $-0.007 \pm 0.056$ & & 0.03 & 0.895 & $-0.150 \pm 0.114$ & 5.30 & 0.197 \\
\hline P. p. ascendens & $9 \mathrm{Apr}$ & $36.93 \pm 15.58$ & $-0.009 \pm 0.004$ & 12.36 & 0.048 & $-0.172 \pm 0.010$ & 8.77 & 0.094 \\
\hline \multicolumn{9}{|l|}{ Full flowering } \\
\hline P. davidiana & $2 \mathrm{Apr}$ & $41.49 \pm 19.04$ & $-0.011 \pm 0.005$ & 12.08 & 0.049 & $-0.266 \pm 0.130$ & 11.93 & 0.049 \\
\hline P. yedoensis & 13 Apr & $36.59 \pm 14.64$ & $-0.009 \pm 0.004$ & 14.77 & 0.023 & $-0.236 \pm 0.010$ & 15.28 & 0.024 \\
\hline P. armeniaca & 14 Apr & $-0.073 \pm 0.068$ & & 2.70 & 0.286 & $-0.191 \pm 0.108$ & 9.09 & 0.088 \\
\hline P. p. ascendens & $14 \mathrm{Apr}$ & $41.88 \pm 14.50$ & $-0.011 \pm 0.004$ & 19.71 & 0.006 & $-0.245 \pm 0.010$ & 17.24 & 0.016 \\
\hline \multicolumn{9}{|l|}{ Flowering speed } \\
\hline P. davidiana & 8.26 & $-0.004 \pm 0.018$ & & 0.13 & 0.806 & $0.004 \pm 0.031$ & 0.07 & 0.882 \\
\hline P. yedoensis & 7.06 & $-0.031 \pm 0.012$ & & 13.41 & 0.009 & $-0.012 \pm 0.019$ & 1.34 & 0.521 \\
\hline P. armeniaca & 6.95 & $-0.045 \pm 0.018$ & & 12.19 & 0.020 & $-0.040 \pm 0.029$ & 5.76 & 0.179 \\
\hline P. p. ascendens & 6.57 & $-0.056 \pm 0.015$ & & 22.44 & $<0.001$ & $-0.073 \pm 0.024$ & 8.95 & 0.005 \\
\hline \multicolumn{9}{|l|}{ First appearance } \\
\hline Pieris rapae & 2 Apr & $0.168 \pm 0.084$ & & 7.93 & 0.053 & $0.213 \pm 0.149$ & 6.60 & 0.163 \\
\hline \multicolumn{9}{|c|}{ Mismatching days } \\
\hline P. davidiana & -6.44 & $-0.215 \pm 0.084$ & & 12.41 & 0.014 & $-0.456 \pm 0.149$ & 24.44 & 0.005 \\
\hline P. yedoensis & 5.77 & $42.59 \pm 21.08$ & $-0.011 \pm 0.005$ & 19.88 & 0.007 & $-0.420 \pm 0.119$ & 30.04 & 0.001 \\
\hline P. armeniaca & 6.67 & $-0.161 \pm 0.076$ & & 8.87 & 0.040 & $-0.350 \pm 0.140$ & 17.70 & 0.018 \\
\hline P. p. ascendens & 6.81 & $49.94 \pm 23.31$ & $-0.013 \pm 0.006$ & 18.50 & 0.011 & $-0.370 \pm 0.140$ & 19.41 & 0.013 \\
\hline
\end{tabular}


$\left(\mathrm{R}^{2}=9.17 \%, \mathrm{p}=0.104\right)$ and the full flowering of $P$. armeniaca $\left(\mathrm{R}^{2}=11.40 \%, \mathrm{p}=0.084\right)$ variability achieved only marginal significance. These significant or almost significant quadratic trends for the period 1953-2002 mean that there was a trend toward later flowering dates to the mid-1970s and that there has
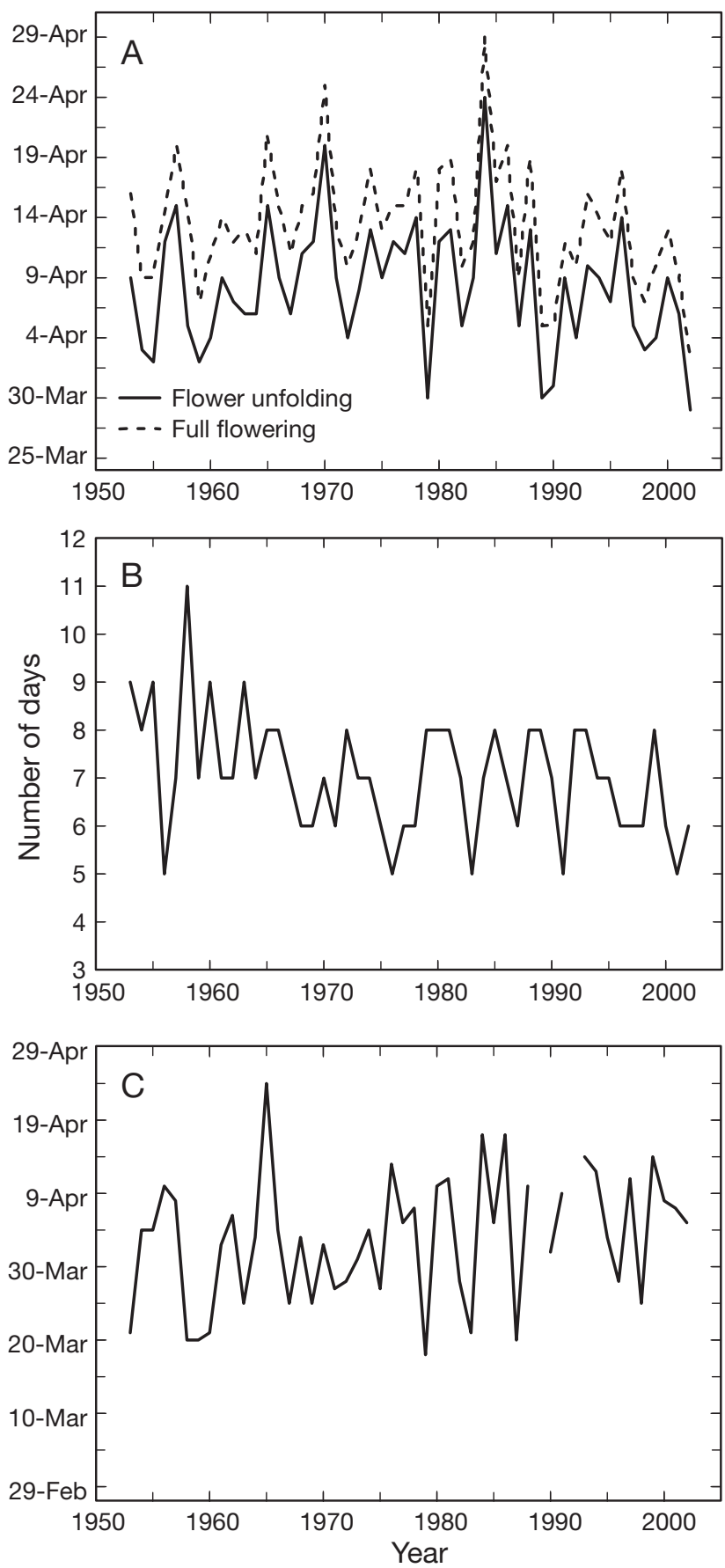

Fig. 1. Prunus yedoensis and Pieris rapae. Temporal trends of selected phenological events. (A) Dates of flower unfolding and full flowering of $P$. yedoensis. (B) Flowering speed of $P$. yedoensis as the number of days between flower unfolding and full flowering. (C) First appearance of the butterfly P. rapae been a trend toward earlier dates since then. The later statement is well supported by the negative trends, significant in almost all cases, of flowering dates for the period 1970-2002 (Table 1). Full flowering models had higher $\mathrm{R}^{2}$ values than flower unfolding models in all species.

There was a negative trend in flowering speed (i.e. shorter periods occur more recently) in Prunus yedoensis, $P$. armeniaca, and $P$. ascendens throughout the entire study period (Table 1, Fig. 1B). The flowering speed was reduced by between 2 and $3 \mathrm{~d}$ between 1953 and 2002 for these species according to the regression slope estimates (see Table 1). Interestingly, this reduction was achieved mainly during the first decades of the study period (Fig. 1B), since in most species there were no significant trends for the period 1970-2002.

Butterfly appearance tended to occur later in more recent years (Table 1, Fig. 1C). As a consequence of this positive trend, there was a clear advancement of flower unfolding with respect to butterfly appearance (i.e. negative trend on mismatching days; Fig. 2). This negative trend in mismatching days has been especially marked since the 1970s (Table 1). Prunus yedoensis, $P$. armeniaca, and $P$. ascendens presently

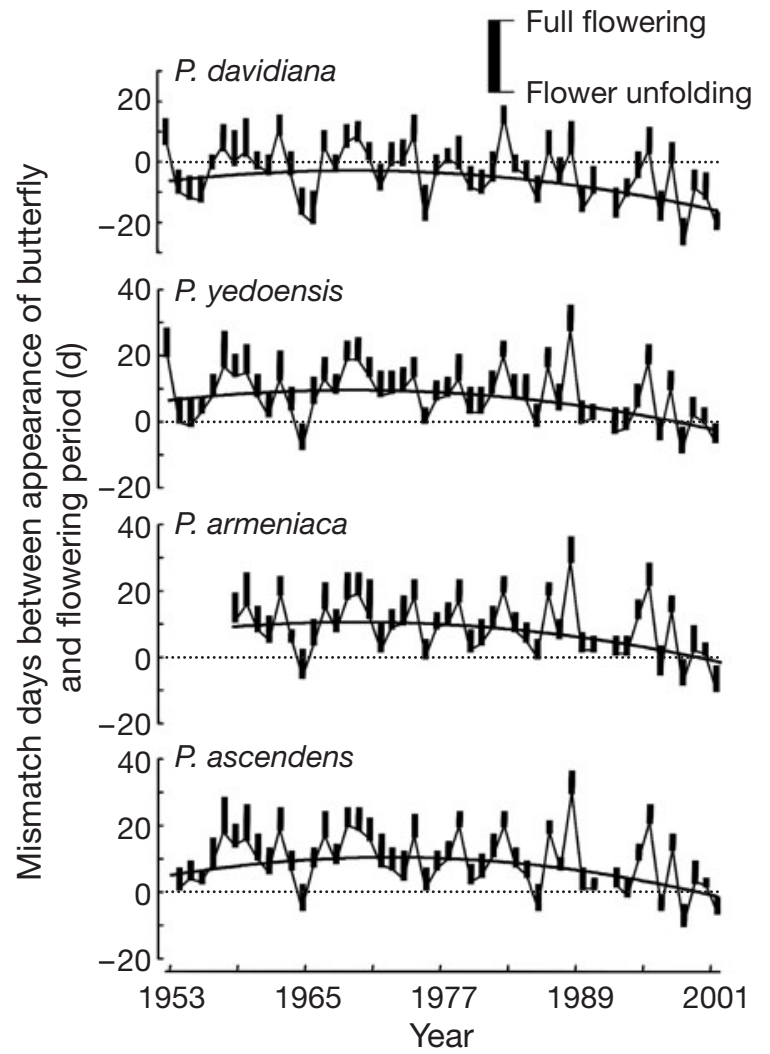

Fig. 2. Prunus spp. and Pieris rapae. Mismatching days between first appearance of adult $P$. rapae and flowering of the 4 Prunus species. Solid lines represent the best quadratic model 
begin flowering prior to butterfly appearance; in contrast, they began flowering an average of $1 \mathrm{wk}$ after the appearance of the first Pieris rapae individuals between the 1950s and 1980s. In some years, e.g. 1998, even full flowering was achieved by the 3 Prunus species before the first butterfly appeared.

\subsection{Temporal trends in climate}

Annual mean temperatures have shown a warming trend since the 1970s, whereas precipitation decreased until the 1980s (Fig. 3). However, only the temperature trend fit significantly to a quadratic model with a turning point in 1970. The annual trends of climate factors, which are usually reported in studies on the impacts of climate change, were not representative of the trends of within-year heterogeneity for either temperature or precipitation. Fig. 4 shows the trend between 1970 and 2002 for all 365 possible intervals within a year for an increasing temporal window from 1 to $60 \mathrm{~d}$. In the case
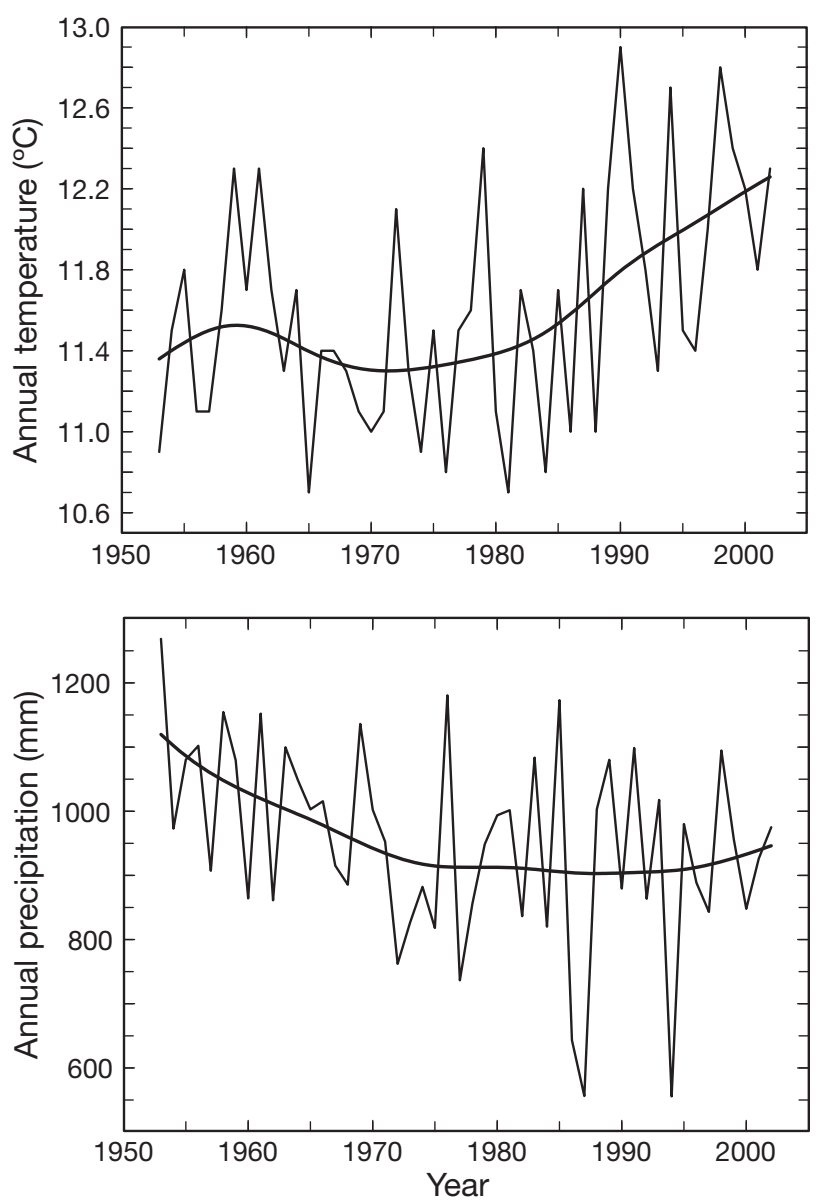

Fig. 3. Temporal trends in annual mean temperature (upper panel, ${ }^{\circ} \mathrm{C}$ ) and total precipitation (lower panel, $\mathrm{mm}$ ) at Nagano Observatory 1953-2002. Solid lines show the smoothed trend according to a distance weighted, least squares function of temperatures, most daily trends were positive, i.e. most days of the year tended to be warmer during the last 3 decades. Nevertheless, some days showed the opposite trend (i.e. cooler temperatures). This yields certain periods within the year (especially with a temporal span shorter than 15 d) with non-significant warming (correlation coefficients around 0) or even cooling (negative coefficients, e.g. the last week of February; Fig. 4). The within-year temporal variation was much higher for precipitation than for temperature. Even a $60 \mathrm{~d}$ temporal window is unable to smooth large differences of daily trends. This interval demonstrates roughly that winter and summer tended to be drier, whereas spring and autumn were moister (Fig. 4).

\subsection{Relationships between phenology and climate}

Fig. 5 summarizes correlation matrices between phenological data and climate. The effect of temperature and precipitation on plant and insect phenology changed during the annual cycle ( $y$-axes) in all time windows examined ( $x$-axes). The alternation of colors along the $y$-axis (i.e. during the annual cycle) means that temperature (Fig. 5a) and precipitation (Fig. 5b) alternate periods with negative and positive effects depending on the time of year. For example, in the case of Prunus tree species, the red color during the end of the winter and the spring preceding flowering dates means that an increase of temperature during those months advances flowering. However, for the same species and event, the light blue color during the preceding autumn (September to November) means that increases in temperature delay flowering dates in the following spring. Only correlation matrices for 2 species ( $P$. davidiana and $P$. ascendens) are shown, since in the rest of the tree species the correlation patterns during the annual cycle and for each temporal window were quite similar. P. davidiana and P. ascendens were selected because they showed the earliest and latest flowering date (see Table 1). In the case of $P$. davidiana, the white color in the left corner of Fig. 5a reflects a decrease in correlation values when the time window starts after the mean date of flowering. Therefore, the best correlations with temperatures are achieved by fine tuning with average flowering dates.

Flower unfolding and full flowering were significantly correlated with temperatures during all periods longer than $5 \mathrm{~d}$, ending at the average occurrence date for each phenological event in all Prunus species (Fig. 6A,B). Nevertheless, inter-annual variability in flowering date was best fitted with longer temporal windows, as shown by progressively larger correlation coefficients with increasing interval spans. The strength of the correlation did not increase beyond 30 to $40 \mathrm{~d}$ 

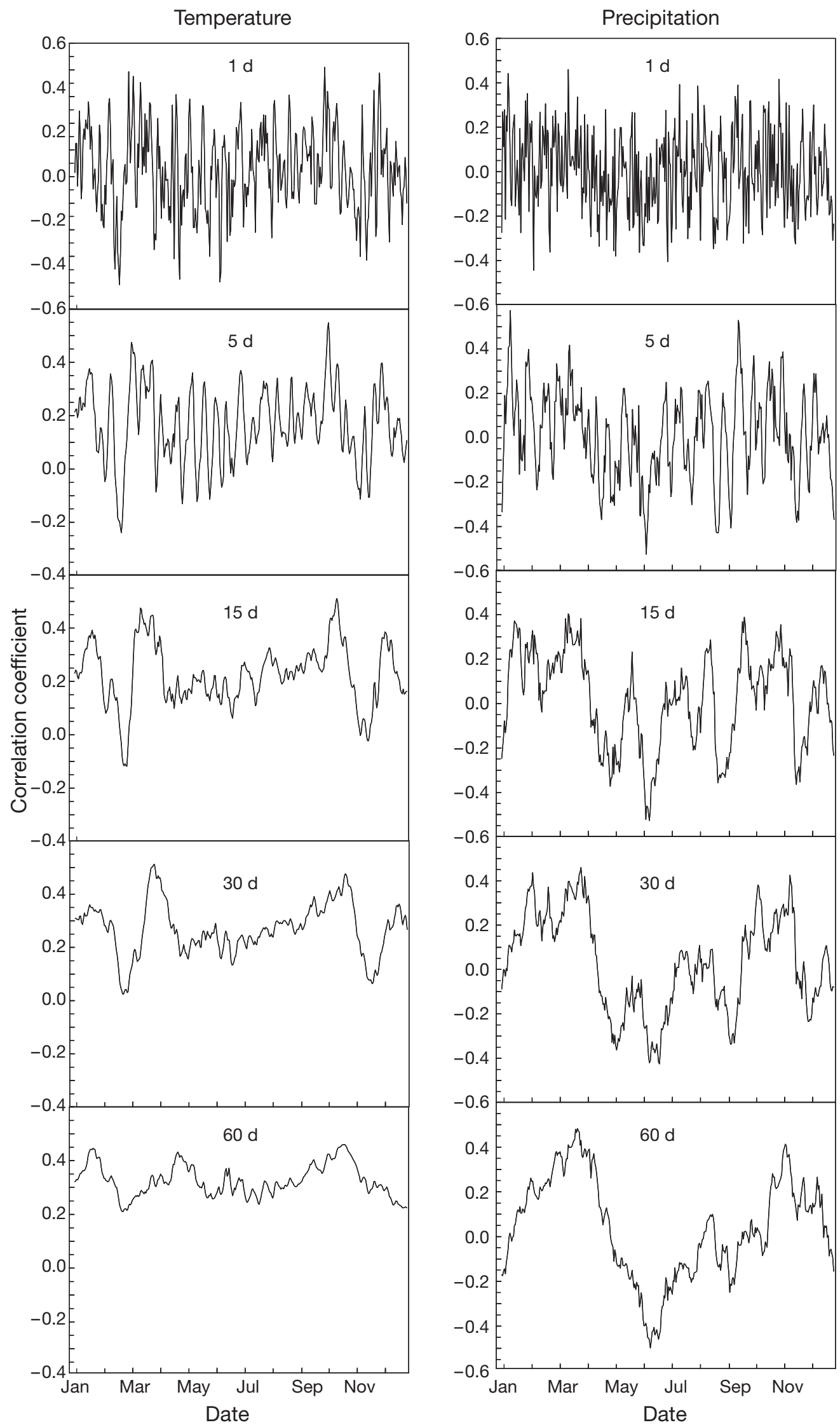

Fig. 4. Temporal trends in within-year mean temperature (left panels, ${ }^{\circ} \mathrm{C}$ ) and total precipitation (right panels, mm) at Nagano Observatory 1970-2002. The $y$-axis represents the correlation coefficient achieved by each time series ending on each day $(y-$ axis). Intervals of $1,5,15$, 30 , and $60 \mathrm{~d}$ are shown. Note that trends can be opposite during short consecutive intervals within the year 
a Temperature

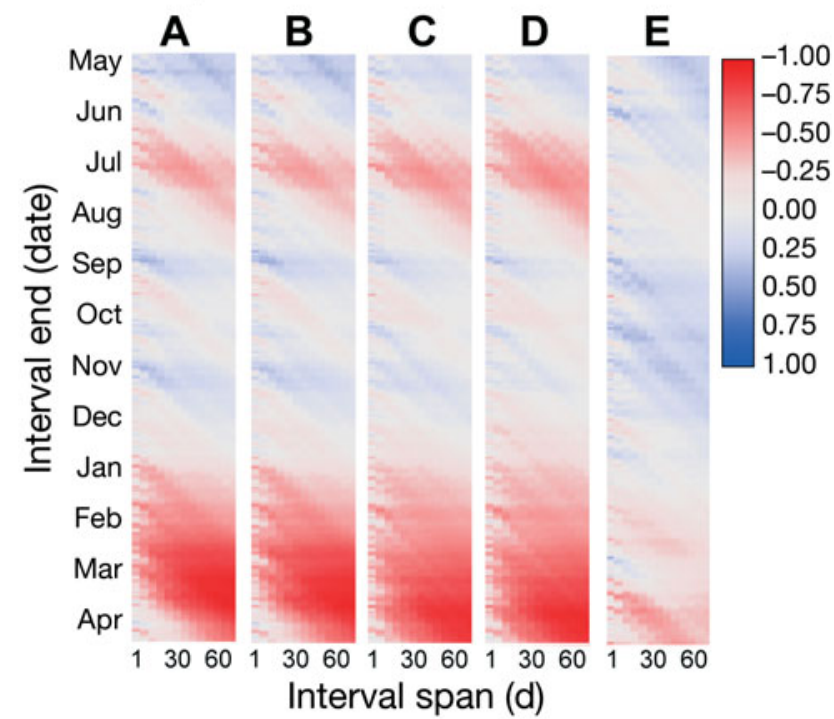

b Precipitation

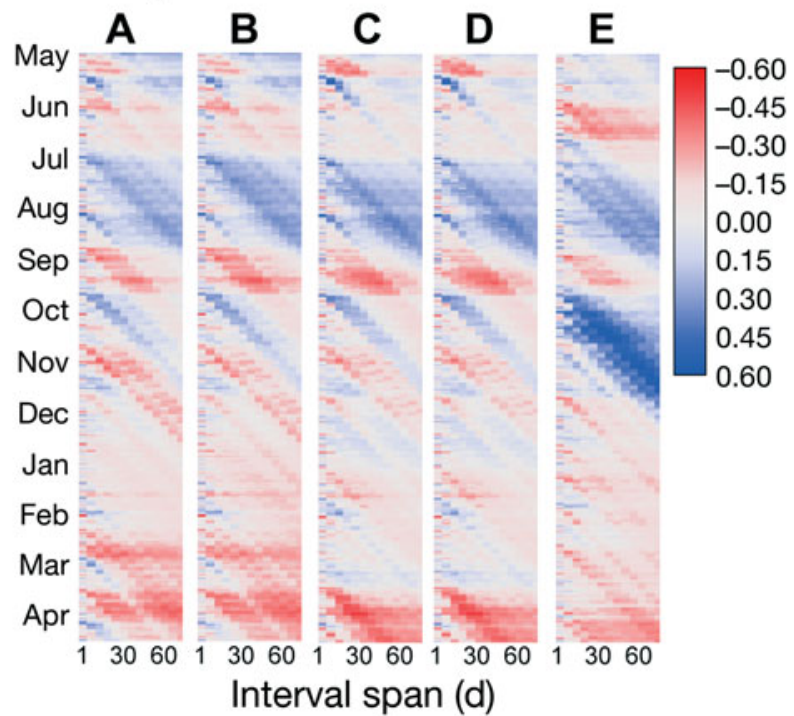

Fig. 5. Prunus spp. and Pieris rapae. Correlation matrices of (a) temperature and (b) precipitation, with (A) flower unfolding and (B) full flowering of $P$. davidiana, (C) flower unfolding and (D) full flowering of $P$. ascendens, and (E) the appearance of $P$. rapae for different intervals during a complete annual cycle (starting on 1 May of the previous year and ending on 30 April of the year in which the event was recorded). The color indicates the strength of the correlation. Positive coefficients (blue) indicate that the event was delayed in response to higher temperatures or precipitation, whereas negative coefficients (red) indicate that the event was advanced

and stabilized at about -0.85 and -0.90 according to species and phase (Fig. 6A,B). Therefore, for these Prunus species, 30 to $40 \mathrm{~d}$ interval preceding the average flowering date is the most sensitive period to temperature. There was a strong relationship between temperature and flowering phenology in another period, i.e. in mid-July of the previous year, in Prunus spp. (Fig. 5a). Warmer temperatures during this period resulted in advanced flowering during the next spring. Interestingly, there was no correlation between temperatures during March or April and temperatures during July of the previous year (March to July: $\mathrm{r}=$ $0.210, \mathrm{p}=0.148$; April to July: $\mathrm{r}=0.061, \mathrm{p}=0.678$ ). Thus, we can reject temperature co-variation within the annual cycle as the origin of this relationship. Nevertheless, the correlation coefficients during this period were about -0.55 , thus notably lower than those found for the 30 to 40 preceding days.

The relationship between flowering and precipitation was also quite similar among the Prunus species (Fig. 5b). There were many periods within the year that affected flowering, both positively and negatively. Thus, the sign of the effect of precipitation alternates depending on the time of year more than in the case of temperature. The amount of rainfall 15 to $20 \mathrm{~d}$ before the average occurrence date of each phenological event had a significant negative effect, i.e. flowering occurred earlier in years with more rainfall during that period. A smaller negative effect was found for rainfall during January. However, rainfall during June and
July of the previous year had a positive effect, i.e. increased rainfall during these months delayed flowering in the next spring. As with temperature, there was no relationship between precipitation in these 3 important periods (analyses not shown), and thus a hypothetical co-variation can be rejected. Overall, the magnitude of correlations between flowering and precipitation were smaller than in the case of temperature (compare values in the keys).

Pieris rapae was less affected by temperature than was Prunus flowering (lighter colors in Fig. 5a), while, in the case of precipitation, the butterfly was a bit more affected than trees (darker colors in Fig. 5b). Nevertheless, the most important feature is again the absolutely different correlation patterns for both variables during the annual cycle. Temperature during the $15 \mathrm{~d}$ prior to the average first appearance of the butterfly had the strongest effect (Fig. 6C). Temperatures between the second half of September and the first half of October of the previous year also had a notable effect (Fig. 6D), although they did not achieve statistical significance. Warmer temperatures during these periods in the preceding autumn delayed butterfly appearance. Rainfall generally had a negative but non-significant effect on butterfly phenology (dominance of light red color in Fig. 5b). The strongest effects were observed for rainfall during the last week of September and the end of October. Rainfall during these periods had a positive effect on butterfly appearance, i.e. more precipitation resulted in a later appearance. 

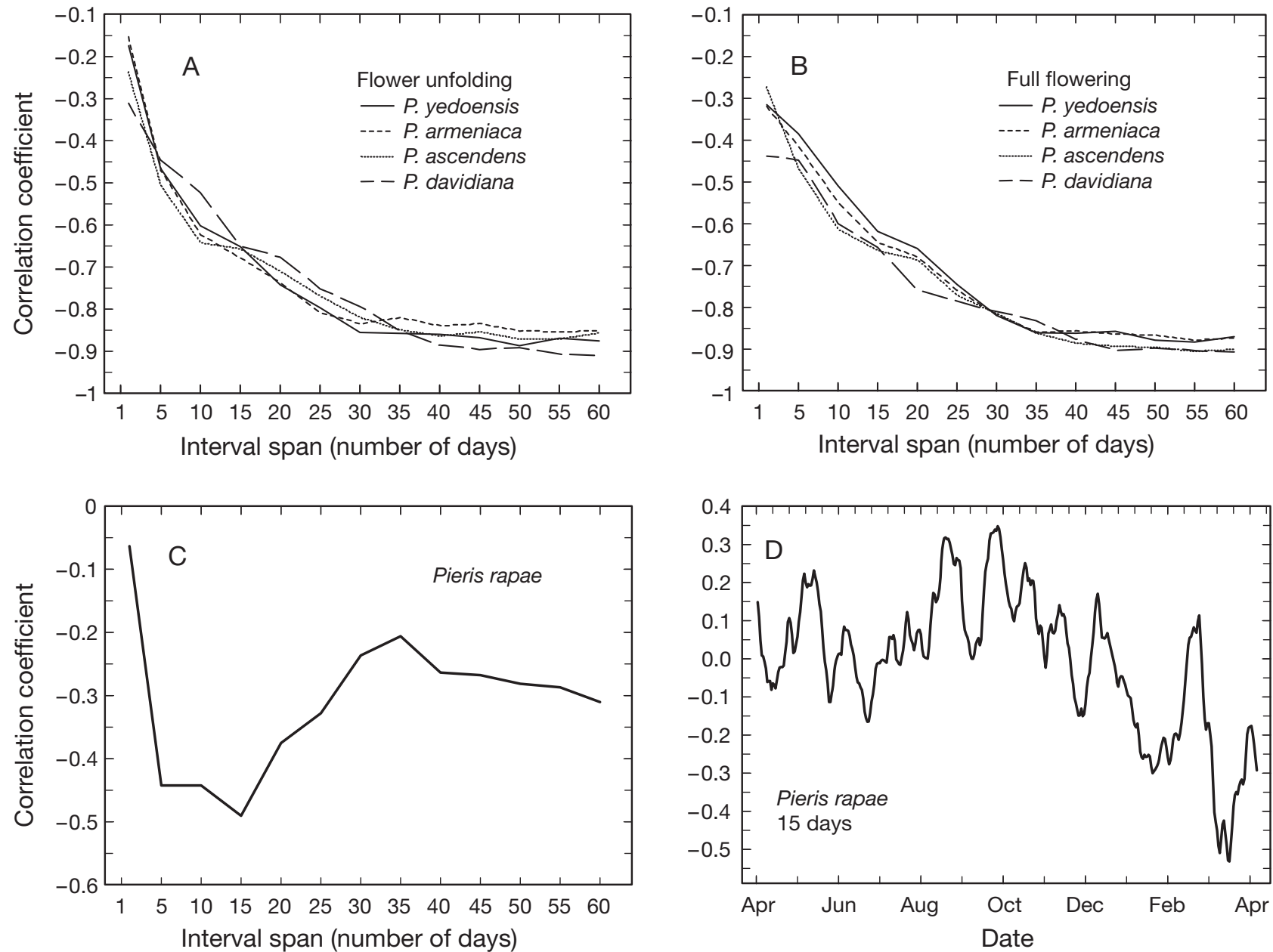

Fig. 6. Prunus spp. and Pieris rapae. Variation in the correlation coefficient between temperature and flowering in 4 Prunus species $(\mathrm{A}, \mathrm{B})$ and between temperature and $P$. rapae appearance $(\mathrm{C})$, with an increasing interval span ending at the average date of each event. (D) Variation in the correlation coefficient between temperature and $P$. rapae appearance during a complete annual cycle (starting on 1 May of the previous year and ending on 30 April of the year in which appearance was recorded) for a temporal window of $15 \mathrm{~d}$. Positive coefficients indicate that butterfly appearance was delayed in response to a temperature increase, whereas negative coefficients indicate that it was advanced

\section{DISCUSSION}

Plant and insect phenologies are affected by different climatic cues. Temperature was the most important climatic variable for both trophic levels, as demonstrated in previous studies (e.g. Gordo \& Sanz 2005, Menzel et al. 2006). However, the best fitting time period (i.e. most sensitive period) for temperature was different for plants and insects. A large time window of approximately 30 to $40 \mathrm{~d}$ prior to flowering was the best fitting temperature period for plants (similar to Gingko biloba budding in Japan: Matsumoto et al. 2003; see also Lu et al. 2006), whereas only the preceding $15 \mathrm{~d}$ were relevant to butterfly appearance. This differing climatic sensitivity has serious consequences for phenological matching between Prunus trees and a potential pollinator of them, the butterfly Pieris rapae.
Temperature during the sensitive period for Prunus has markedly increased during the last decades (correlation between temperature and year for the period from 1970 to $2002 ; \mathrm{r}=0.472, \mathrm{p}=0.006$ ), causing earlier flowering in all species (see Table 1). However, on a shorter temporal scale within a year, such as that driving butterfly phenology, temporal trends in temperature are more variable (see Fig. 4). In fact, the average temperature for the $15 \mathrm{~d}$ preceding butterfly appearance has not increased significantly (correlation between the temperature and year for the period from 1970 to $2002 ; r=0.331, p=0.060)$. As a consequence of these different trends in the temperature-sensitive period in Prunus species and $P$. rapae, the phenological adjustment to climate change differs; flowering occurs earlier, whereas butterfly appearance occurs later. At the beginning of the study period, Prunus flowered 
after butterflies appeared. Therefore, $P$. rapae could pollinate Prunus trees. However, at present, Prunus trees flower before $P$. rapae arrive, and P. rapae cannot be a potential pollinator during the early stages of Prunus flowering.

It is not clear to what extent the changes that we observed are representative of plant-pollinator interactions. Warming effects depend on the species involved (Kudo et al. 2004), on micro-scale climatic conditions (Kudo \& Hitai 2006), or on geographical regions (Tryjanowski et al. 2006). For example, spring ephemerals in a deciduous forest in Hokkaido, Japan, that are pollinated by bees and bumblebees (Hymenoptera) have dramatically lower seed-set in warm years because of pollen limitation (Kudo et al. 2004). Hymenoptera use maximum daily temperature as a cue to end hibernation, whereas spring ephemerals use spring temperature and snowmelt as cues to begin flowering. In warm years, spring ephemerals flower earlier, but are not pollinated because the Hymenoptera are still in hibernation. A large-scale study on the Iberian Peninsula (Gordo \& Sanz 2006) showed that temporal phenological trends of and climatic effects on Pieris rapae are quite similar to those of another important pollinator, the honey bee Apis mellifera. Therefore, our study may be indicative of a spread of mismatching between Prunus and other pollinators as well.

The negative effects of a potential mismatching between Prunus species and their pollinators could be amplified by the quickening of the flowering, and thus the reduction of time available for pollination. Most previous studies have focused on the onset of flowering (i.e. flower unfolding), while long-term changes in other flowering measures, such as full flowering date, have been rarely evaluated (e.g. Estrella et al. 2007). Here, the advancement of flowering occurred at the same or an even higher rate in later stages of the flowering cycle. Therefore, we found not just a phenological shift, but also a complete alteration of the entire flowering event.

The overwhelming majority of previous studies have used climatic variables with a monthly time span (e.g. Menzel et al. 2006, Estrella et al. 2007). However, this definition is arbitrary and imposed by the human calendar. Few studies have searched for the period during which climatic variables are best related to phenological events (e.g. Matsumoto et al. 2003, Ahola et al. 2004, Lu et al. 2006). Our results highlight the importance of assessing particular climate changes during the key period for phenology. Annual trends in climate parameters are usually reported, but they give little information on changes within shorter time spans (see Figs. $3 \& 4$ ) that are relevant to a species' phenology. Annual temperatures at Nagano, Japan, have increased in agreement with global warming trends
(Easterling et al. 1997). However, the sensitive period of Pieris rapae did not experience warming, and, consequently, the appearance of the butterfly was not advanced, which is counterintuitive based only on the annual trend. Therefore, future studies should use climatic variables designed ad hoc to phenological events, rather than monthly values, because of heterogeneous climate trends within a year (Easterling et al. 1997, Gordo \& Sanz 2005).

A delayed effect of climate on the phenology of organisms was found. Plant flowering phenology was significantly affected by temperatures during July and August of the preceding year (see Fig. 5a), and precipitation during the same period also significantly affected flowering (see Fig. 5b). Annual precipitation peaks during this period at Nagano. Both temperature and precipitation were positively associated with flowering: warmer and drier summers were associated with earlier flowering dates in the following spring. Prunus flower buds grow in summer; thus, the effects of ecological conditions experienced during their development appear in the flowering phenology in the next spring. Delayed effects of temperature have been noted previously (e.g. Fitter et al. 1995, Sparks et al. 2000), although they were restricted to the preceding autumn or winter and were attributed to vernalization. To the best of our knowledge, this is the first report of a delayed effect of the preceding summer on spring plant phenology. Rather than peculiarities of Prunus species, the summer effect can be attributed to intraannual climate patterns in Japan. Therefore, additional studies from other regions with different climatic patterns are necessary because the climate control of phenology could differ regionally (Tryjanowski et al. 2006).

Acknowledgements. We sincerely thank the agents of the Japan Meteorological Agency for collecting the long-term phenological and climate data. We also thank Aqua Restoration Research Center, Japan, for helping us to write this paper. This research was supported by the Japan Society for the Promotion of Science to H. Doi.

\section{LITERATURE CITED}

Ahola M, Laaksonen T, Sippola K, Eeva T, Rainio K, Lehikoinen E (2004) Variation in climate warming along the migration route uncouples arrival and breeding dates. Glob Change Biol 10:1610-1617

Bale JS, Masters GJ, Hodkinson ID, Awmack C and others (2002) Herbivory in global climate change research: direct effects of rising temperature on insect herbivores. Glob Change Biol 8:1-16

> Both C, Visser ME (2001) Adjustment to climate change is constrained by arrival date in a long-distance migrant bird. Nature 411:296-298

Doi H (2007) Winter flowering phenology of Japanese apricot 
Prunus mume reflects climate change across Japan. Clim Res 34:99-104

Doi H, Katano I (2008) Phenological timings of leaf budburst with climate change in Japan. Agric For Meteorol 148: 512-516

Easterling DR, Horton B, Jones PD, Peterson TC and others (1997) Maximum and minimum temperature trends for the globe. Science 277:364-367

Estrella N, Sparks TH, Menzel A (2007) Trends and temperature response in the phenology of crops in Germany. Glob Change Biol 13:1737-1747

Fitter AH, Fitter RSR, Harris ITB, Williamson MH (1995) Relationships between first flowering date and temperature in the flora of a locality in central England. Funct Ecol 9:55-60

Gordo O, Sanz JJ (2005) Phenology and climate change: a long-term study in a Mediterranean locality. Oecologia 146:484-495

Gordo O, Sanz JJ (2006) Temporal trends in phenology of the honey bee Apis mellifera (L.) and the small white Pieris rapae (L.) in the Iberian Peninsula (1952-2004). Ecol Entomol 31:261-268

Harrington R, Woiwod I, Sparks TH (1999) Climate change and trophic interactions. Trends Ecol Evol 14:146-150

Inoue $\mathrm{T}$ (2004) Community structure of butterflies in the forestry and forest production research institute, Tsukuba, Ibaraki prefecture, central Japan. Bulletin of Forestry \& Forest Products Research Institue 392:221-247 (in Japanese with English summary)

Inouye DW, Barr B, Armitage KB, Inouye BD (2000) Climate change is affecting altitudinal migrants and hibernating species. Proc Natl Acad Sci USA 97:1630-1633

JMA (1985) Guidelines for the observation of phenology, 3rd edn. Japan Meteorological Agency, Tokyo (in Japanese)

Jonzén N, Ergon T, Lindén A, Stenseth NC (eds) (2007) Bird migration and climate. Clim Res 35:1-180

Kudo G, Hirao AS (2006) Habitat-specific responses in the flowering phenology and seed set of alpine plants to climate variation: implications for global-change impacts. Popul Ecol 48:49-58

Kudo G, Nishikawa Y, Kasagi T, Kosuge S (2004) Does seed production of spring ephemerals decrease when spring comes early? Ecol Res 19:255-259

Lu PL, Yu Q, Liu JD, He QT (2006) Effects of changes in spring temperature on flowering dates of woody plants across China. Bot Stud (Taipei, Taiwan) 47:153-161

Matsumoto K, Ohta T, Irasawa M, Nakamura T (2003) Climate change and extension of the Ginkgo biloba L.

Editorial responsibility: Mauricio Lima, Santiago, Chile growing season in Japan. Glob Change Biol 9:1634-1642

Memmott J, Craze PG, Waser NM, Price MV (2007) Global warming and the disruption of plant-pollinator interactions. Ecol Lett 10:710-717

> Menzel A (2003) Plant phenological anomalies in Germany and their relation to air temperature and NAO. Clim Change 57:243-263

Menzel A, Sparks TH, Estrella N, Koch E and others (2006) European phenological response to climate change matches the warming pattern. Glob Change Biol 12:1969-1976

> Parmesan C (2006) Ecological and evolutionary responses to recent climate change. Annu Rev Ecol Evol Syst 37: 637-669

- Root TL, Price JT, Hall KR, Schneider SH, Rosenzweig C, Pounds JA (2003) Fingerprints of global warming on wild animals and plants. Nature 421:57-60

Sparks TH, Jeffree EP, Jeffree CE (2000) An examination of the relationship between flowering times and temperatures at the national scale using long-term phenological records from the UK. Int J Biometeorol 44:82-87

Sparks TH, Dennis RLH, Croxton PJ, Cade M (2007) Increased migration of Lepidoptera linked to climate change. Eur J Entomol 104:139-143

Stenseth NC, Mysterud A (2002) Climate, changing phenology, and other life history traits: nonlinearity and matchmismatch to the environment. Proc Natl Acad Sci USA 99:13379-13381

Tryjanowski P, Panek M, Sparks TH (2006) Phenological response of plants to temperature varies at the same latitude: a case study of dog violet and horse chestnut in England and Poland. Clim Res 32:89-93

> Visser ME, Both C (2005) Shifts in phenology due to global climate change: the need for a yardstick. Proc R Soc Lond B Biol Sci 272:2561-2569

Visser ME, Holleman LJM (2001) Warmer springs disrupt the synchrony of oak and winter moth phenology. Proc R Soc Lond B Biol Sci 268:289-294

Visser ME, Both C, Lambrechts MM (2004) Global climate change leads to mistimed avian reproduction. Adv Ecol Res 35:89-110

- Walther GR, Post E, Convey P, Menzel A and others (2002) Ecological responses to recent climate change. Nature 416:389-395

Wolfe DW, Schwartz MD, Lakso AN, Otsuki Y, Pool RM, Shaulis NJ (2005) Climate change and shifts in spring phenology of three horticultural woody perennials in northeastern USA. Int J Biometeorol 49:303-309

Submitted: October 26, 2007; Accepted: February 21, 2008 Proofs received from author(s): April 21, 2008 